\title{
OVERVIEW OF THE DIGITAL HYDRAULIC ACTUATOR (DHA) CONCEPT FOR AIRCRAFT
}

\author{
Ivan Jr. Mantovani \\ Federal University of Santa Catarina - UFSC \\ Florianópolis, Santa Catarina, Brazil \\ Henri C. Belan \\ Federal Institute of Santa Catarina - IFSC \\ Tubarão, Santa Catarina, Brazil
}

\author{
Vinícius Vigolo \\ Federal University of Santa Catarina - UFSC \\ Florianópolis, Santa Catarina, Brazil \\ Victor J. De Negri \\ Federal University of Santa Catarina - UFSC \\ Florianópolis, Santa Catarina, Brazil
}

\begin{abstract}
Research of new conceptions for aircraft actuators are gaining prominence, mainly due to the low energy efficiency of the current dominant systems in the sector. More Electrical Aircraft - MEA is a concept that has guided the realization of several researches on electro-mechanical (EMA) and electro-hydrostatic actuators (EHA). Airbus A380 and Boeing 787, for instance, present some innovations with origin in these researches. However, for safety reasons, the primary control surfaces are normally driven by conventional servo-hydraulic systems, which leaves this subject open to new researches. Presented this scenario, the Laboratory of Hydraulic and Pneumatic Systems LASHIP, the Division of Fluid and Mechatronic Systems - FLUMES, and the Svenska Aeroplan AB - SAAB started the development of a new conception of flight surface actuation, applying digital fluid power strategies, thus appointing the Digital Hydraulic Actuator - DHA. In this scope, this abstract aims to present all the steps of the DHA development, furthermore, shows the research's status and future challenges to bring closer academic studies with the aero industry. The extended abstract was organized through a timeline with all publications about the DHA concept written by these research groups. Also, the existing research project is presented, where the goals are the solution of intrinsic problems of the digital hydraulic systems and the reliability analysis of this concept.
\end{abstract}

Keywords: Digital Hydraulic Actuator, Digital Hydraulics, Aircraft Actuator, Energy Efficiency

\section{INTRODUCTION}

The advent of research about new conceptions for flight control actuation systems is undeniable, for example, More Electrical Aircraft - MEA is a concept that has guided the realization of several researches on Electro-Mechanical (EMA) and Electro-Hydrostatic Actuators (EHA), cited by [1], flight control actuation experts from Airbus in the R3ASC in 2018, France. Still, according to by [1, 2], advantages of MEA includes weight and costs saving, aircraft manufacturing cost and lead time, overall reliability and availability of systems, maintainability, and environmental footprint. However, for safety reasons (jamming in fault), the primary control surfaces are driven by conventional servo-hydraulic systems [1], which leaves this subject open to new researches of aircraft actuator systems as safe as the conventional actuators, however highly efficiency.

The advantages and disadvantages of traditional hydraulic systems are widely known, among them, the great villain in aviation is the low energy efficiency, since reducing the power consumption, and thus the fuel burn, is a major target for the next generation of aircraft [3]. In this decade, researches about digital fluid power gained visibility in congresses and journals of fluid power [4], mainly because this technology offers several new ways to implement highly efficient hydraulic systems [5], in other words, solving the main disadvantage of traditional hydraulic systems.

Currently, research centers with greater emphasis on digital hydraulic are located in Tampere, Finland, whose laboratory's head is Matti Linjama, and in Linz, Austria, with Bern Winkler as laboratory's head. Analyzing their last publications, it is observed the interest in the digital switching valves [6] and fault studies on digital systems [7]. According to [4, 8], it is possible to highlight the research centers in the following countries: United Kingdom, Germany, Denmark, France, United State American, Russia, Bulgaria, and China, where there are digital fluid power researches.

Involved in this scenario of aviation and digital fluid power, the Laboratory of Hydraulic and Pneumatic Systems - LASHIP of the Federal University of Santa Catarina - UFSC from Brazil and the Division of Fluid and Mechatronic Systems - FLUMES of the Linköping University - LiU from Sweden, in a partnership with the company Svenska Aeroplan $\mathrm{AB}$ - SAAB from Sweden, started a research about the use of the digital hydraulic for primary flight control actuation system. This partnership produced the first publication in 2014, since then, two master theses, a doctoral thesis, and a development and research project were concluded, also an experimental test bench was built for proof of concept. 
This extended abstract presents a timeline with all publication related to the research and development of the Digital Hydraulic Actuator (DHA). The timeline starts in 2014 [9] and includes the publications made until the present date. In the end, the current search state will also be presented. Thereby, the reader will know the DHA development process and the current and future challenges.

\section{HISTORICAL}

Figure 1 presents a timeline of the Digital Hydraulic Actuator (DHA) development publications. This timeline exposes all steps related to the DHA concept development and the experimental bench building, furthermore, the beginning of the current processes of this development.

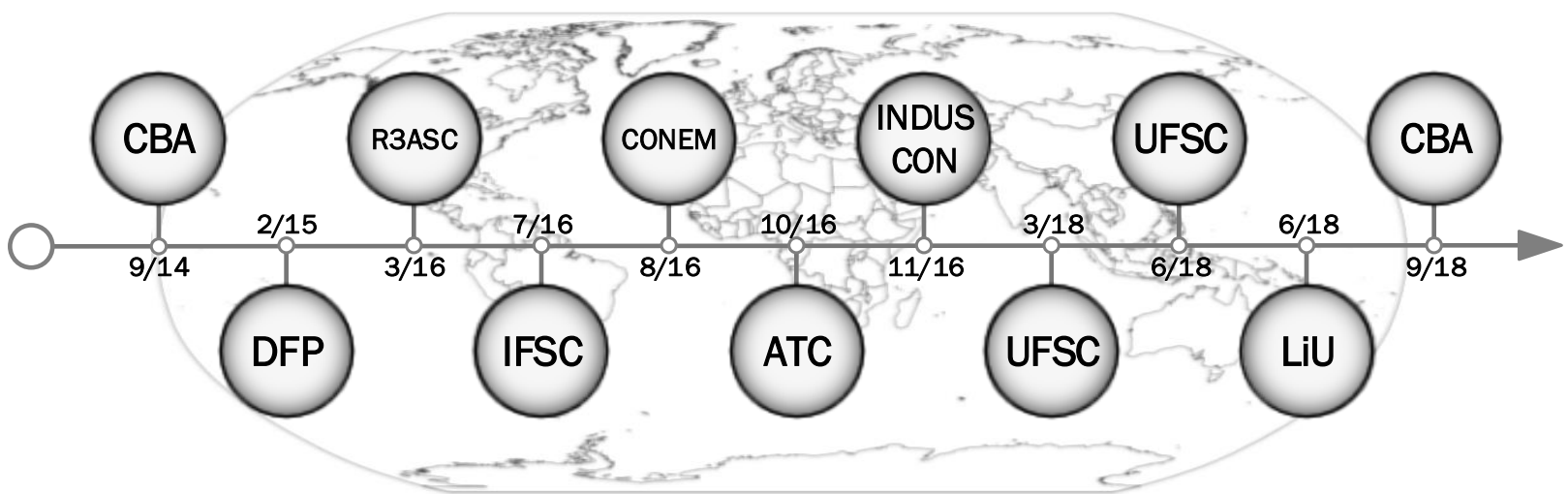

Figure 1 -Timeline of the Digital Hydraulic Actuator (DHA) development publication

The first publication [9] (CBA - 9/14) is considered the first one about digital fluid power published in Brazil. In this paper, new researches about the technology were discussed, as well as a classification of digital hydraulic systems, according to traditional hydraulic systems, are suggested, which are: Conditioning unit and reservoir, primary conversion unit, limitation and control unit and secondary conversion unity. The main results of this publication were the motivation of Brazilian researchers about digital hydraulics and the proposal of common technical terms in Portuguese [9].

In next year, with the paper [10] (DFP - 2/15), the first idea to use a digital secondary control for linear actuator to be used in aircraft is described. The proposed system is composed of three pressure lines, a valve-pack of 12 on/off valves and multichamber tandem cylinder. The valve-pack connects the three pressure lines with each cylinder's chamber generating 81 different forces, which is the result of the combination between pressures and areas, and it is made by a specific combination of on/off valves activation. This hydraulic circuit concept is used until today. The paper also presents the description of two Matlabß routines used to determine the multichamber piston's areas and pressures levels of the system. These routines are the main tools in designing this system for a given application.

The term Digital Hydraulic Actuator (DHA) is introduced in [11] (R3ASC - 3/16), where a more detailed version of the system proposed in [10] is presented. In this paper, safety components are added and the possibility of two different reservoir pressure levels are considered, which results in a more robust system and the possibility to obtain 256 discrete force values. New discussions are presented in the context, such as the reduction of heat production in the aircraft which leads to a further weight and energy saving, and system reliability which is expected to be higher due to the number of valve's redundancy. The applicability to aircraft is also pointed out, thus the redundant pressure sources and the pressurized reservoir can be used for the three pressure lines of the DHA. On the other side, few challenges are also addressed, for instance, the different dynamics of the on/off valves, which requires the development of a controller capable to identify dynamically the optimum time delay to be applied to the digital valves in order to improve the piston's movement and avoid dissipative actions.

The switching time of the on/off valves is analyzed with more details in [12] (IFSC - 7/16). This paper is a final term paper, therefore it was published in [13] (INDUSCON - 11/18), where the main objective is the development of an electronic device to accelerate the switching time of the valves. The strategy used to reduce the switching time of the digital valves is called Peak and Hold, it consists of applying a voltage peak for a short period of time, increasing the valve's acceleration and afterward reduce the voltage to lower value, which might be even lower than its nominal voltage. Several experiments were performed to analyze the valve's response to different peak times and peak voltages, where a saturation of the switching time was observed as a function of the peak time. The minimum switching time was obtained with the highest peak voltage $(48 \mathrm{~V})$ and a peak time of $3 \mathrm{~ms}$, the hold voltage of $6 \mathrm{~V}$, which is half of the nominal voltage, was capable to keep the valve open and also reduce the valve's temperature. With this configuration of Peak and Hold, the opening time was reduced from $14 \mathrm{~ms}$ to $4.7 \mathrm{~ms}$, the closing time was reduced from $50 \mathrm{~ms}$ to $44 \mathrm{~ms}$ and the dissipated power was reduced from $14.4 \mathrm{~W}$ to $8.2 \mathrm{~W}$. 
The digital hydraulics test bench design and construction is described in [14] (CONEM - 8/16), where the main objective is the experimental validation of the Digital Hydraulic Actuator concept. The test bench uses a conventional power unit with just one pressure line, the other two pressure levels are obtained from a pressure control block, where two pressure reducing valves are used to reduce the high pressure from the power unit to the other two pressure levels. The system load is obtained by a set of five metal blocks, which weights $18.5 \mathrm{~kg}$ each one, and spring with an elastic constant of $27.56 \mathrm{kN} / \mathrm{m}$, which results in a total force of $8.63 \mathrm{kN}$.

In the paper [15] (ATC - 10/16), the use of the digital hydraulic instead of the conventional circuits in aircraft application is discussed. The considered aspects were control design, safety, and energy issues. In the control context, the use of switched control theory and modern control approach, for instance $\mathrm{H} \infty$, showing the feasibility of the approach is explored. Regarding safety aspects, redundancy is a common practice to increase reliability, thus it is pointed out that the redundancy is intrinsic in the digital hydraulic due the parallel valves. Finally, with respect to energy issues, numerical results showed that the digital hydraulic had a significant increase in energy efficiency, which can be as large as $80 \%$ compared to conventional circuits.

At this stage of the research the idealizer of the DHA's concept concluded his doctoral thesis [16] (UFSC - 3/18), this document makes a complete description of the previously mentioned steps, furthermore, the first experimental results of test bench are presented. The main objective of the doctoral thesis was to develop a control strategy, for the digital hydraulic system, capable to result in a good performance in terms of energy efficiency. Thus, the control structure was implemented using a feedback control, with PI control and an adaptative gain, and a simple feedforward control, compensating the spring force and friction force. With this control structure, an efficiency gains of 90\% was reached in comparison with the traditional hydraulic systems used in aircraft.

Three months later two master theses were concluded, one in LASHIP [17] (UFSC - 6/18), and other in FLUMES [18] (LiU - 6/18). The first one had the main objective the comparison of conventional hydraulic systems with digital hydraulic systems regarding energy efficiency, considering the internal leakage of servo-valves. Results showed that in a common movement of the aileron, the DHA have a reduction of about $93 \%$ when compared with a servant-led hydraulic system with internal leak. The second master thesis was focused on safety analysis, it had two main objectives, which were the reliability analysis and the fault analysis of the DHA. The results include a method to calculate the reliability of the system and the fault analysis concluded that DHA is not fault tolerant by default but can be if designed correctly.

\section{CURRENT OBJECTIVES}

Currently, a project to bring together a new consortium was started, consisting of SAAB and LiU in Sweden, UFSC and CERTI in Brazil, to collaborate with further development of the DHA. Safety and redundancy will mainly be addressed and a diagnostic function will be developed to handle the requirements. It includes the study of sensor technology to be incorporated in the system and further development of the test rig to provide means to assess the performance. In parallel with this project, there is a master thesis in progress, which aims to improve the performance of the system and maintain energy efficiency, through an analysis of the switching between valves and its variables. The beginning of this research already produced a paper [19] (CBA - 9/18).

\section{CONCLUSION}

The system presented in this extended abstract is part of a research which started in 2014, the research has already proved some outstanding advantages of a digital hydraulic actuator over traditional hydraulic systems, but it also has some limitations. In the pursuit to solve the drawbacks of the proposed system, eight papers and three theses have been published in the last four years. The present abstract describes the steps taken during this research and outlined the most relevant difficulties and accomplishments, allowing the reader to have a complete overview of the Digital Hydraulic Actuator technology.

\section{ACKNOWLEDGMENTS}

$\mathrm{AB})$.

The authors are grateful to FAPESC (Santa Catarina Research Foundation) and the SAAB (Svenska Aeroplan

\section{REFERENCES}

[1] Larrineu, N., Lamoussiere, X., Andrieu L. "AIRBUS Research and Perspectives for Aircraft Control Actuation," Recent Advances in Aerospace Actuation Systems and Components. Toulouse, France. pp. 1-5, Jun 2018.

[2] Sarlioglu B., Morris C. T. "More Electric Aircraft: Review, Challenges, and Opportunities for Commercial Transport Aircraft," IEEE Transactions on Transportation Electrification. Volume 1: Number 1. Jun 2015. 
[3] Palmieri, M., Pispola, G., Curri, D., Braccesi, C., Cianetti, F. "Electromechanical actuation for landing gear application: A case study on end-stroke impact in case of high speed free-fall emergency extension.," Recent Advances in Aerospace Actuation Systems and Components. Toulouse, France. pp. 69-76, Jun 2018.

[4] Winkler, B. "Recent Advances in Digital Hydraulic Components and Applications," The Ninth Workshop on Digital Fluid Power. Aalborg, Denmark. Sep 2017.

[5] Linjama, M. "Digital Fluid Power - State of the Art," The Twelfth Scandinavian International Conference on Fluid Power. Tampere, Finland. May 2011.

[6] Bender, N. C., Pedersen, H. C., Plockinger, A., Winkler, B. "Reliability Analysis of a Hydraulicon/Off Fast Switching Valve," The Ninth Workshop on Digital Fluid Power. Aalborg, Denmark. Sep 2017.

[7] Ersfolk, J., Ahopelto, M., Lund, W., Wiik, J., Waldén, M., Linjama, M., Westerholm J. “Online Fault Identification of Digital Hydraulic Valves Using a Combined Model-Based and Data-Driven Approach,” Computer Science. Mar 2018.

[8] Scheidl, R., Winkler, B., Plöckinger A, "Digital Fluid Power in the 7th Year of DFP Workshops," The Seventh Workshop on Digital Fluid Power. Linz, Austria. pp 4-8. Feb 2015.

[9] Belan, H. C.; Locateli, C. C.; De Pieri, E. R.; De Negri, V. J. "Aumento da Eficiência Energética em Sistemas Hidráulicos Utilizando Hidráulica Digital,” XX Congresso Brasileiro de Automática- CBA, Belo Horizonte-MG, Brasil, 2014.

[10] Belan, H. C., Locateli, C. C., Lantto, B., Krus, P., De Negri, V. J. "Digital Secondary Control Architecture for Aircraft Application,” The Seventh Workshop on Digital Fluid Power. Linz, Austria. Feb 2015.

[11] Belan, H. C., Krus, P., Lantto, B., De Negri, V. J. "Digital Hydraulic Actuator (DHA) Concept for Aircraft Actuation Systems," Recent Advances in Aerospace Actuation Systems and Components. Toulouse, France. Mar 2016.

[12] Bregalda, R. "Development and Analyses of Electronic Device to Accelerate Solenoid Valves for Application in Digital Hydraulic," End of Course Work - Federal Institute of Santa Catarina - IFSC. Chapecó - SC, Brazil. Jul 2016.

[13] Bregalda, R.; Kulman, C.; Belan, H. C. "Development and Analyses of Electronic Device to Accelerate Solenoid Valves for Application in Digital Hydraulic," In: 12th IEEE/IAS International Conference on Industry Applications INDUSCON, Curitiba-PR, Brazil. Nov 2016.

[14] Belan, H. C., Fallgatter, R. H., Bregalda, R., De Negri, V. J.” Sizing and Implementation Technique for a Digital Hydraulic System,” IX Congresso Nacional de Engenharia Mecânica. Fortaleza - CE, Brazil. Aug 2016.

[15] Pinto, L. P. G., Belan, H. C., Locateli, C. C., Krus, P., De Negri, V. J., Lantto, B. "New perspectives on digital hydraulics for aerospace applications," Aerospace Technology Congress. Solna, Stockholm. Oct 2016.

[16] Belan, H. C. "Digital Hydraulic Actuation System for Aircraft with Focus in Energy Efficiency," Doctor thesis. In: Federal University of Santa Catarina - UFSC. Florianópolis-SC, Brazil. Mar 2018.

[17] Cruz, D. P. M. “Analyses of the Digital Hydraulic System for Aircraft with Focus in Energy Efficiency,” Master thesis. In: Federal University of Santa Catarina - UFSC. Florianópolis-SC, Brazil. Jun 2018.

[18] Pettersson R. "Safety Analysis on Digital Hydraulic," Master thesis. In: Linköping University - LiU. Linköping, Sweden. Jun 2018.

[19] Mantovani, I, J., Belan, H. C., De Negri, V. J. "Analyses of Switching Between Valves for Digital Hydraulic Actuator (DHA),”XXII Congresso Brasileiro de Automática. João Pessoa-PB, Brazil. Set 2018. 